\title{
Response summation and noncontingent reinforcement
}

\author{
DONALD MELTZER and BRUCE NIEBUHR \\ Southern Illinois University, Carbondale, Illinois 62901
}

\begin{abstract}
A series of experiments showed that if a subject was reinforced for responding separately to two discriminative stimuli, light and tone, their simultaneous presentation increased responding during extinction. However, if the subject was reinforced for responding to light, and tone preceded noncontingent reinforcement, the simultaneous presentation of light and tone did not increase responding.
\end{abstract}

A number of experiments have demonstrated the phenomenon of additive summation using operant procedures. In a typical experiment (e.g., Meltzer \& Masaki, 1972; Weiss, 1969), responses were reinforced on the same schedule during each of two stimuli and were never reinforced in their absence. However, the simultaneous presentation of the two stimuli caused the subject to respond at a higher rate than when each stimulus was presented alone. The increased rate occurred even though the schedule remained the same during simultaneous and separate stimulus presentations.

The demonstration of summation of operant responses extended the range of conditions under which the summation phenomenon could be observed. Konorski (1948) and Pavlov (1927) had previously shown the same result. They demonstrated that dogs made stronger conditioned salivary responses when conditioned stimuli (CSs) were presented together than when each was presented alone. These earlier studies suggest the possibility that the summation of operant responses might be more complex than was first imagined.

For example, do subjects show summation of operant responses because of stimulus control of the operant responses themselves or because these stimuli elicit classically conditioned mediating responses? Several recent theories have presented accounts of how mediation of instrumental responses might occur (e.g., Boakes, 1979; Overmier \& Lawry, 1979; Rescorla \& Solomon, 1967). If such hypotheses are correct, response summation might actually be produced because of the summation of classically conditioned anticipatory responses. Since a response during either of the component stimuli led to the same reinforcement in most response summation studies, not only would the instrumental response be the same during each component stimulus, but anticipatory responses would also be identical.

The summation of anticipatory responses that are similar because they precede the same reinforcement is consistent with what Overmier and Lawry (1979) have called an "affective" model of mediation and which they compared with another view of mediation that they called the "associative" model. In the latter case, a discriminative stimulus elicited a mediating response that had stimulus properties for both the response to be emitted and the reinforcement to be received. According to this view, summation should occur only when stimuli elicit mediating responses associated with the same instrumental response. Thus, one might find that a classically conditioned stimulus that preceded food would not cause an increase in response rate when it was presented while the subject was making instrumental responses for food reinforcement. There is support for such a hypothesis. Soltysik, Konorski, Holownia, and Rentoul (1976) conditioned dogs to make a paw flexion response that was reinforced with food when a discriminative stimulus was present. They then paired each of several other stimuli with food in a classical conditioning procedure. When these CSs were presented while the dog was making the instrumental response, there was no increase in response rate.

Other studies have also reported failures to increase the probability of appetitively reinforced instrumental responses during a CS that preceded an appetitive unconditioned stimulus (UCS) (e.g., Azrin \& Hake, 1969; Karpicke, Christophe, Peterson, \& Hearst, 1977; Miczek \& Grossman, 1971). But a number of studies have also shown facilitation of instrumental responses when an appetitive CS was presented (e.g., LoLordo, McMillan, \& Riley, 1974; Meltzer \& Hamm, 1974, 1978). In the latter cases, the CS was usually of longer duration. However, none of the experiments other than Soltysik et al. (1976) required that the subjects' instrumental responses be brought under discriminative control. Thus the Soltysik et al. study remains the one most closely approximating the response summation procedure in which two discriminative stimuli are used.

The experiments in this paper examined the effects of compounding a discriminative stimulus with a conditioned stimulus to determine whether response summation could be explained as the summation of mediating responses. 
Table 1

Mean Number of Responses During Light and During Light Plus Tone in the Extinction Session

\begin{tabular}{lllc}
\hline & & \multicolumn{2}{c}{ Stimulus } \\
\cline { 3 - 4 } Group & $\mathrm{n}$ & Light & Light Plus Tone \\
\hline Experimental & 6 & 35.8 & 65.5 \\
Control & 6 & 40.5 & 37.5 \\
Mean & & 38.15 & 51.5 \\
\hline
\end{tabular}

in the yoked control group during the different stimulus conditions. The experimental subjects had been reinforced for responding to both light and tone and showed response summation. The control subjects had only been required to respond to light and did not show response summation.

\section{EXPERIMENT 2}

In the preceding experiment, the lever had been removed from the chamber when tone was presented to subjects in the yoked control group, and the terminal acquisition performance of the two groups was different. It was possible that the response summation that was demonstrated in the experimental group was due to a number of factors. It may have been caused by the fact that experimental subjects had to respond to tone and control subjects did not, by the higher rates of the experimental subjects at the end of conditioning and during extinction, or simply by the larger number of sessions during which experimental subjects had to press the lever. In this experiment, the number of sessions during which subjects had to press the bar was equated for the two groups. The experimental group still responded in the presence of both discriminative stimuli, whereas the yoked control subjects were allowed to respond only when one of the stimuli was present.

\section{Method}

Subjects. Fourteen 90 -day-old hooded rats served as subjects. They were maintained on the same schedule of water deprivation as animals in the first experiment, and sessions again were scheduled 5 days/week.

Apparatus. The apparatus was the same as that used in the first experiment.

Procedure. The subjects were shaped to press the bar and placed on a variable-interval (VI) $20-\mathrm{sec}$ schedule during the first five sessions. The light was always on during these sessions.

After this initial training, the subjects were placed on a chain VI $40-\mathrm{sec} /$ VI $20 \mathrm{sec}$ schedule that had previously been shown to produce summation. In this procedure, there was a period with a mean value of $40 \mathrm{sec}$ during which neither the light nor the tone was on. The first response after the end of this interval turned on the light. The light remained on for an average of $20 \mathrm{sec}$, and the first response after the end of this interval produced the water reinforcement and turned off the light. The cycle then began again. Sessions ended when the subject had earned 30 reinforcements.

After 10 sessions, the subjects were divided into two groups, and each experimental subject was paired with a yoked control subject. Subjects in the control group continued with the same procedure they had experienced in the first 10 sessions. Subjects in the experimental group no longer responded for reinforcement. The bar was removed from their chamber, and they experienced the same sequence of a period of darkness lasting a mean duration of $40 \mathrm{sec}$, followed by a period of light lasting a mean duration of $20 \mathrm{sec}$, and ending with water presentation. The onset of light and the delivery of water depended upon the performance of the control subject for both paired animals. Each session continued until subjects in the control group had earned 30 reinforcements.

During the next stage of the experiment, the bar was removed from the chamber of the yoked control subjects and replaced in the chamber of the experimental subjects. Subjects that had been paired in the preceding stage remained paired in this one. The reinforcement schedule during this stage of the experiment remained chain VI $40 \mathrm{sec} /$ VI $20 \mathrm{sec}$, but the light was never turned on. Instead, the tone was presented during the last part of the chain. Thus, experimental subjects experienced a period of silence that lasted a mean of $40 \mathrm{sec}$. The first response at the end of that interval turned on the tone, which lasted a mean of $20 \mathrm{sec}$. The first response at the end of that interval produced reinforcement and terminated the tone. Subjects in the control group also experienced the sequence of silence, followed by tone, terminating with water presentation. However, the onset of tone and the delivery of water depended upon the performance of the rat's paired experimental subject. Each session continued until the experimental subjects had earned 30 reinforcements, and there were 10 such sessions.

During the last two sessions prior to testing, the bars were available to the subjects in both groups, and the procedure was the same as in the first stage of the experiment. That is, a chain VI $40-\mathrm{sec} /$ VI $20-\mathrm{sec}$ schedule was in effect, and the light was turned on during the last segment of the chain. Tone was never turned on during these two sessions.

Testing took place during the last session, which was an extinction session. There were 10 presentations of light and 10 presentations of light plus tone in a random order. Average duration of the stimuli was $20 \mathrm{sec}$, and between each stimulus was a period of darkness and silence that averaged $40 \mathrm{sec}$ in duration.

\section{Results}

Response rates during the last acquisition session were analyzed to determine whether terminal performances of the two groups were equal. Subjects in the experimental group responded at a mean rate of 10.0 responses/min during darkness and 32.0 responses/min during light. Subjects in the control group responded at a mean rate of 11.4 responses/min during darkness and 30.1 responses/min during light. Although rates were significantly higher during light $[F(1,12)=49.12$, $\mathrm{p}<.01]$, there was no significant difference between the groups, nor was there a significant interaction between groups and stimuli.

There was no overall difference in the rates at which the two groups responded during the extinction session. However, the subjects responded at a mean rate of 9.18 responses/min during the light stimulus and at a mean rate of 13.53 responses/min during light plus tone. That difference was significant $[F(1,12)=10.22$, $p<.01]$. There was also a significant interaction $[F(1,12)=10.09, p<.01]$ between group and stimulus condition, which is shown in Table 2 . It is apparent that subjects that had responded during the presence of tone in the conditioning phase of the study made more responses during light plus tone than they did during light alone. There was no such difference between 


\section{EXPERIMENT 1}

\section{Method}

Subjects. Twelve 90-day-old hooded rats served as subjects. The rats were on a 23-h water-deprivation schedule and were given free access to water for $15 \mathrm{~min}$ following each experimental session. Experimental sessions were scheduled 5 days/ week.

Apparatus. The experimental chamber was manufactured by LVE (Model 1316) and was equipped with one bar, located approximately $2.8 \mathrm{~cm}$ above the floor and $3.8 \mathrm{~cm}$ from the left wall. There was a small pilot light approximately $2.5 \mathrm{~cm}$ above the bar. A .03-cc dipper was mounted at the base of the front wall, midway between the two bars. The chamber was completely dark when the pilot lights were off. When both lights were on, the illumination was $9.04 \mathrm{~mL}$ when measured with the light meter facing the front wall at a distance of $5.0 \mathrm{~cm}$ behind either bar. The ambient noise level produced by the blower was $63 \mathrm{~dB}$, and the auditory stimulus used in the experiment was a 714- $\mathrm{Hz}$ tone that increased the noise level by $4 \mathrm{~dB}$.

Procedure. All subjects were shaped to press the bar during the first session. They were reinforced for every response during the next two sessions and for every 10th response during the three sessions after that. At that point, the subjects were divided into two groups of six rats each.

During the next session, the subjects in each group were reinforced on a multiple schedule. No responses were reinforced during a $20-\mathrm{sec}$ period of darkness. At that time, the light was turned on and the rat was reinforced after completing 10 responses. When reinforcement was delivered, the light was turned off and the 20 -sec extinction interval began again. The sequence of light and dark intervals was continued until the subject had earned 30 reinforcements.

The light was never turned on during the next session. Subjects in the experimental group were presented with a tone until they completed 10 responses and were then reinforced with water. The tone was turned off for $20 \mathrm{sec}$ and no responses were reinforced. The tone was then turned on again, and the fixed-ratio schedule resumed until reinforcement. The alternation of silence and tone intervals continued until the subject had earned 30 reinforcements. Subjects in the yoked control group had no bar available during this session. Their chamber was also in darkness throughout the session, and they, too, experienced $20 \mathrm{sec}$ of silence followed by a tone that terminated with water delivery. However, the duration of the tone and the time at which water was delivered depended entirely upon the performance of the paired subject in the experimental group. When the experimental subject completed 10 responses, water was presented in both the experimental and the yoked control chambers, and the tone was turned off in both chambers. This session continued until both experimental and control subjects had received 30 water reinforcements.

Sessions in which light preceded reinforcement and both subjects pressed the bar alternated with sessions in which tone preceded reinforcement and one subject served as a yoked control until there had been 15 sessions of each type.

The final session was a test session in which responses were extinguished. There were $1020 \mathrm{sec}$ presentations of light and $1020-\mathrm{sec}$ presentations of light plus tone in a quasirandom sequence. Between each of these stimulus presentations, there was a 20 -sec period of darkness and silence. Tone alone was not included in the extinction session because the control group had never responded in the presence of tone.

\section{Results}

The final acquisition performance of subjects in the experimental group in each type of session (i.e., the last session during which light preceded reinforcement and the last session during which tone preceded reinforcement) was analyzed. In the former condition, they pressed the bar at a mean rate of 25.5 responses/min during darkness and 68.1 responses/min during light. In the latter condition, they pressed the bar at a mean rate of 27.8 responses/min during silence and 94.0 responses/min during tone. Rates were significantly higher when the positive stimulus was on than when the extinction schedule was in effect $[F(1,5)=19.41$, $\mathrm{p}<.01]$. The interaction between sessions in which different positive stimuli were used and stimulus condition was also significant $[F(1,5)=11.83, p<.025]$. Tests of simple main effects compared response rate during tone, in those sessions in which tone was the positive stimulus, to response rate during light, in those sessions in which light was the positive stimulus. The mean rate of 94.0 responses/min during tone was significantly higher than the mean rate of 68.1 responses/min during light $[F(1,5)=28.53, p<.01]$. However, there was no significant difference between extinction response rates in the two types of schedules.

Another analysis compared the performance of the experimental and control subjects during their last acquisition session. Light was the positive stimulus for subjects in both groups. Experimental subjects responded at a mean rate of 68.1 responses/min when the light was on and 25.5 responses/min when the light was off. Control subjects responded at a mean rate of 36.6 responses/min when the light was on and 16.1 responses/min when the light was off. The difference between the groups was significant $[F(1,10)=17.53$, $\mathrm{p}<.01]$, as was the difference between mean rates in light and darkness $[F(1,10)=92.05, p<.01]$. However, the interaction between groups and stimulus conditions was also significant $[F(1,10)=11.32, p<.01]$. Tests of simple main effects showed that subjects responded at significantly higher rates during light in both the experimental $[F(1,10)=83.98, p<.01]$ and control groups $[F(1,10)=19.49, p<.01]$. But, when the light was on, subjects in the experimental group responded at significantly higher rates than did subjects in the control group $[F(1,10)=45.90, p<.01]$, whereas there was no significant difference in the response rates of the two groups when the light was off.

The number of responses each subject made in light and in light plus tone was recorded during the extinction session. The subjects in the experimental group made an average of 101.3 responses during extinction, and the yoked control subjects made an average of 78.0 responses. However, the difference was not significant. The mean number of responses during light plus tone was 51.5 , and the mean number of responses during the light alone was 38.15 ; this difference was significant $[F(1,10)=14.70, p<.01]$. The interaction between stimulus condition and group was also significant $[F(1,10)=22.06, p<.01]$ and is shown in Table 1 . An analysis of simple main effects showed that subjects in the experimental group made more responses during light plus tone than during light $[F(1,10)=36.38$, $\mathrm{p}<.01]$ but that there was no significant difference between the numbers of responses made by subjects 
Table 2

Mean Response Rates of Both Groups of Subjects During Light and During Light Plus Tone

\begin{tabular}{llrc}
\hline & & \multicolumn{2}{c}{ Stimulus } \\
\cline { 3 - 4 } \multicolumn{1}{c}{ Group } & $\mathrm{n}$ & Light & Light Plus Tone \\
\hline Experimental & 7 & 7.11 & 15.78 \\
Control & 7 & 11.25 & 11.29 \\
Mean & & 9.18 & 13.53 \\
\hline
\end{tabular}

response rates in the presence of the different stimuli for subjects that had not responded to tone during conditioning. A test of simple main effects showed that only the difference in the former group was significant $[F(1,12)=20.31, p<.01]$. These differences were present even though the number of sessions during which subjects made instrumental responses, and their terminal acquisition response rates, were equivalent. As in the first experiment, experimental subjects that had been required to respond to both stimuli showed response summation. Control subjects had been required to respond only to one of the stimuli and did not show response summation.

\section{DISCUSSION}

The results of these studies show that the response summation that occurs when two discriminative stimuli are presented simultaneously is, at least under these conditions, a summation of instrumental responses. Just as Soltysik et al. (1976) found, a stimulus that preceded noncontingent water delivery did not increase responding to a discriminative stimulus. Such a result is consistent with Overmier and Lawry's (1979) view that an interaction between instrumentally and classically conditioned responses can produce different results in different situations. In this case, the subjects in control groups may have responded to the tone in a manner incompatible with barpressing. If so, simultaneous presentation of light and tone during extinction would have resulted in either the same or a lower rate of barpressing compared with the rate during light alone. The fact that any anticipatory response during light would have had to be maintained by water reinforcement, just as would any response to tone, might have been expected to cause the affective components of responses to light and tone to summate. However, such a situation has often failed to produce an increase in the strength of instrumental responses during transfer-of-control experiments, just as it failed to produce summation in this study.

The failure to produce summation in the control groups also had implications for Weiss' (1978) explanation of response summation, which is that summation will occur only when the component stimuli differ from other stimuli in the experimental situation by being associated both with different reinforcement frequencies and with different response probabilities. Obviously, light and tone in these experiments were both associated with high reinforcement frequencies, whereas the absence of both stimuli was a condition of nonreinforcement. However, only the light stimulus was associated with the instrumental response. If Weiss' interpretation of the response factors needed to produce summation is restricted to mean "instrumental response" factors, these results support his hypothesis.

\section{REFERENCES}

Azrin, N. H., \& Hake, D. F. Positive conditioned suppression: Conditioned suppression using positive reinforcers as the unconditioned stimuli. Journal of the Experimental Analysis of Behavior, 1969, 12, 167-173.

BoAkes, R. A. Interactions between Type I and Type II processes involving positive reinforcement. In $\mathbf{A}$. Dickinson \& $\mathbf{R}$. A. Boakes (Eds.), Mechanisms of learning and motivation. Hillsdale, N.J: Erlbaum, 1979.

Karpicke, J., Christophe, G., Peterson, G., \& Hearst, E. Signal location and positive vs. negative conditioned suppression in the rat. Journal of Experimental Psychology: Animal Behavior Processes, 1977, 3, 105-118.

Konorsk1, J. Conditioned reflexes and neuron organization. Cambridge: Cambridge University Press, 1948.

LoLordo, V. M., McMillan, J. C., \& Riley, A. L. The effects upon food-reinforced pecking and treadle-pressing of auditory and visual signals for response-independent food. Learning and Motivation, 1974, 5, 24-41.

Meltzer, D., \& Hamm, R. J. Conditioned enhancement as a function of schedule of reinforcement. Bulletin of the Psychonomic Society, 1974, 3, 99-101.

Meltzer, D., \& Hamm, R. J. Differential conditioning of conditioned enhancement and positive conditioned suppression. Bulletin of the Psychonomic Society, 1978, 11, 29-32.

Meltzer, D., \& Masaki, M. A. Stimulus parameters producing response summation. Psychonomic Science, 1972, 29, 155-157.

Micze K, K. A., \& Grossman, S. P. Positive conditioned suppression: Effects of CS duration. Journal of the Experimental Analysis of Behavior, 1971, 15, 243-247.

Overmier, J. B., \& Lawry, J. A. Pavlovian conditioning and the mediation of behavior. In G. H. Bower (Ed.), The psychology of learning and motivation (Vol. 13). New York: Academic Press, 1979.

Pavlov, I. P. [Conditioned reflexes. An investigation of the physiological activity of the higher nervous activity of the cerebral cortex] (G. V. Anrep, trans.). London: Oxford University Press, 1927.

Rescorla, R. A., \& Solomon, R. L. Two process learning theory: Relationships between Pavlovian conditioning and instrumental learning. Psychological Review, 1967, 74, 151-182.

Soltysik, S., Konorski, J., Holownia, A., \& Rentoul, T. The effect of conditioned stimuli signalling food upon the autochthonous instrumental response in dogs. Acta Neurobiologiae Experimentalis, 1976, 36, 277-310.

WEISs, S. J. Attentional processes along a composite stimulus continuum during free-operant summation. Journal of Experimental Psychology, 1969, 82, 22-27.

WEISS, S. J. Discriminated response and incentive processes in operant conditioning: A two factor model of stimulus control. Journal of the Experimental Analysis of Behavior, 1978, 30, 361-381.

(Received for publication September 21, 1981.) 